\title{
THE INFLUENCE OF PLASMA GAS ON CHANGES IN CHEMICAL COMPOSITION AND STRUCTURES DURING THE CUTTING PROCESS
}

\author{
Agnieszka Rzeźnikiewicz, Jacek Górka
}

\author{
Silesian University of Technology, Mechanical Engineering Faculty, Department of Welding Engineering, \\ Konarskiego 18a, 44-100 Gliwice, Poland
}

Corresponding author: Agnieszka Rzeźnikiewicz, agnieszka.rzeznikiewicz@ polsl.pl

\begin{abstract}
Cutting is usually one of initial and basic operations of the manufacturing process of welded structures and realization constructions elements. Thermal cutting, in particular plasma arc cutting is often used to prepare elements. The plasma arc cutting process involves melting and ejecting the liquid metal from the cutting gap with a highly concentrated plasma electric arc which is generated between the non-consuable electrode and the workpiece. The paper presents the results of research on the influence of plasma gas on structural changes and chemical compositions changes resulting unalloyed steel cutting by air plasma arc. It was shown that in the air plasma arc cutting process the amorphous layer with a very high nitrogen content (about 1.6\%) and a hardness of 750 HV 0.2 was used. This high nitriding effect is due to the diffusion of nitrogen from the plasma gas. As a result of the interaction of air plasma arc gases on the liquid metal, the cutting surface is carburized (about $0.5 \%$ ). The alloy components are also burnt according to the theory of selective oxidation of chemical elements. The material structure after the air plasma cutting process shows the structures between the structure formed after oxygen cutting processs and nitrogen plasma cutting process. The process of argon-hydrogen plasma cutting has the least influence on the cut material.
\end{abstract}

Key words: plasma, plasma arc, plasma gases, structural changes, chemical composition changes, air plasma, argonhydrogen plasma, nitrogen plasma cutting process

\section{INTRODUCTION}

Cutting is meant the separation of the material along its entire thickness along a defined parting line, usually perpendicular to the surface of the workpiece. Cutting process variations are: bevelling, gouging and piercing [1-3]. Cutting is usually one of initial and basic operations of the manufacturing process of welded structures and realization constructions elements. Thermal cutting, in particular plasma arc cutting is often used to prepare elements. The plasma arc cutting process involves melting and ejecting the liquid metal from the cutting gap with a highly concentrated plasma electric arc which is generated between the non-consuable electrode and the workpiece. This method has been widely used for thermal cutting of alloy steels and non-ferrous metals (which cannot be cut with oxygen cutting). It is also widely used for cutting carbon and low-alloy steels, in place of the existing oxygen cutting. All gases used in welding can be used for plasma cutting: argon, nitrogen, hydrogen, helium, oxygen and mixtures with hydrocarbon additives [4-7]. During cutting process, these gases affect in the materials structural, chemical changes and cut surface structural in the adjacent layer to the cutting material. These gases also affect the operational properties of the finished elements or on the proprietary welded joints [8-11]. Because of the new materials used into nozzles and electrodes (zirconium, hafnium embedded in a copper or silver body) and using air or oxygen as plasma gas we can obtain good cutting quality and high economic effects $[2,5]$. Oxygen and air belong to the group of active gases that significantly affect to the cut surfaces, causing them to oxidize. This is especially disadvantageous during cutting alloy steels and aluminum alloys. Air is the more preferred plasma gas because of economic reasons. The heataffected zone (HAZ) formed during air plasma cutting has worse properties and structure than the edges obtained during cutting with other plasma gases (argon, argon + nitrogen), bacause of the active influence of these gases on the cutting material [5, 12-15]. The width, type of structure and HAZ hardness during plasma cutting depend on the thickness of the cutting material and the cutting speed. In the case of cutting carbon steels, regardless of the cutting environment, a matrenzitic-bainitic structure is obtained right next to the cut surface [12]. During cutting high-strength steels, significant hardening of the surface areas to about $850 \mathrm{HV}$ is observed. During cutting high-alloy steels (ferritic steels), high stresses and hardening of the cut surface occur in the HAZ due to the high heating and cooling speed [14]. 


\section{MATERIALS AND METHODOLOGY}

Research of the influence of plasma gas on structure changes and chemical compisition changes of the cutting material was carried out on sheets of nonalloy steel S275JR with a thickness of $\mathrm{g}=14 \mathrm{~mm}$. It was cut with air plasma, argon-hydrogen plasma and nitrogen plasma. The chemical composition of the sheets was tested on the MC20 BAIRD emission spectrometer. Chemical composition of investigated material is shown in Table 1 .

Table 1. Actual chemical composition of $14 \mathrm{~mm}$ thick S275JR steel

\begin{tabular}{|c|c|c|c|c|c|c|c|c|}
\hline \multicolumn{1}{|c|}{ Contents of chemical elements, \% by weight } \\
\hline $\mathrm{C}$ & $\mathrm{Si}$ & $\mathrm{Mn}$ & $\mathrm{Ni}$ & $\mathrm{Cr}$ & $\mathrm{Cu}$ & $\mathrm{Al}$ & $\mathrm{P}$ & $\mathrm{S}$ \\
\hline 0.20 & 0.32 & 1.24 & 0.06 & 0.08 & 0.11 & 0.02 & 0.019 & 0.021 \\
\hline
\end{tabular}

To determine the effect of plasma arc gases on chemical and structural changes at the cut surface, a cutting process was carried out using:

$>$ Air as a plasma gas: cutting process parameters:

- cutting current: $\mathrm{I}=250[\mathrm{~A}]$;

- plasma gas pressure: $\mathrm{p}=0.40[\mathrm{MPa}]$;

- cutting speed: $\mathrm{v}=700[\mathrm{~mm} / \mathrm{min}]$.

$>$ Nitrogen as a plasma gas: cutting processs parameters:

- cutting current: $\mathrm{I}=100[\mathrm{~A}]$;

- plasma gas pressure: $\mathrm{p}=0.45[\mathrm{MPa}]$;

- cutting speed: $\mathrm{v}=300[\mathrm{~mm} / \mathrm{min}]$.

$>$ Argon - hydrogen mixture $\left(65 \% \mathrm{Ar}+35 \% \mathrm{H}_{2}\right)$ as

a plasma gas: cutting processs parameters:

- cutting current: $\mathrm{I}=250[\mathrm{~A}]$;

- plasma gases pressure: $\mathrm{Ar}-40[1 / \mathrm{min}], \mathrm{H}_{2}-30$

[1/min];

- cutting speed: $\mathrm{v}=600[\mathrm{~mm} / \mathrm{min}]$.

The selected parameters are optimal in terms of cutting quality and efficiency.

\subsection{Experimental test}

The cut surfaces were tested:

- microsopic metallographic tests on the Axiovert 405M light microscope by OPTON;

- hardnes measurement on a Wilson Wolpert MVD1 hardness tester, with a load of $200 \mathrm{~g}$;

- Changes to chemical equipment on the Jeol ICXA 733 X-ray microanalyzer equipped with an X-ray dispersed emission energy detector (EDS) connected to the OXFORD ISIS 300 analysis system;

- analysis phases created on cuts surface and in the material cut for the PHILIPS PW $1050 \mathrm{X}^{\prime}$ Change device working in the B-B geometry (BraggBrenten).

The samples were etched with nital to reveal the structure of the samples.

\section{RESULTS AND DISCUSSION}

\subsection{Structural changes at the cutting surface}

The metallographic tests and surface hardness measurements after cutting allowed to determine the width of the HAZ and to determine the effect of plasma gas on the width of the zone of structural changes taking place in the cut material. During air plasma cutting, the width of HAZ was $0.7 \mathrm{~mm}$, during the nitrogen plasma cutting process, the HAZ width was $1.2 \mathrm{~mm}$, and for argon-hydrogen plasma HAZ width was $0.9 \mathrm{~mm}$. The differences in the width of the HAZ obtained during cutting with air plasma, nitrogen plasma and argon-hydrogen plasma result from the difference in the enthalpy of the plasma gases used. The metallographic tests (Figures 1-3) and hardness measurements of samples cut with air plasma, nitrogen plasma, and argon-hydrogen plasma allowed to determine the type of structural changes at the cut surface.

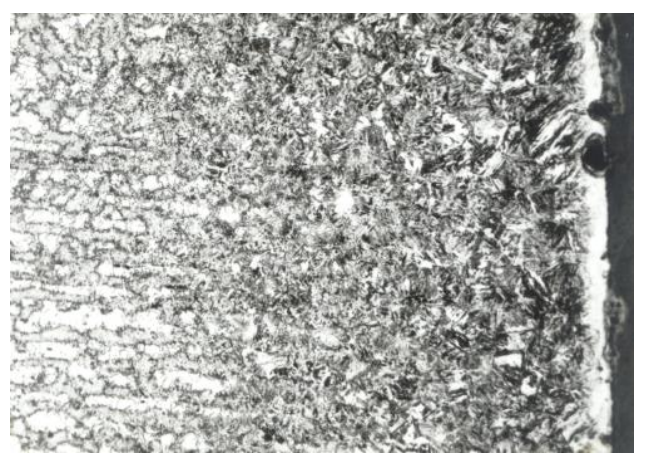

Fig. 1. Microstructure at the air plasma cut surface

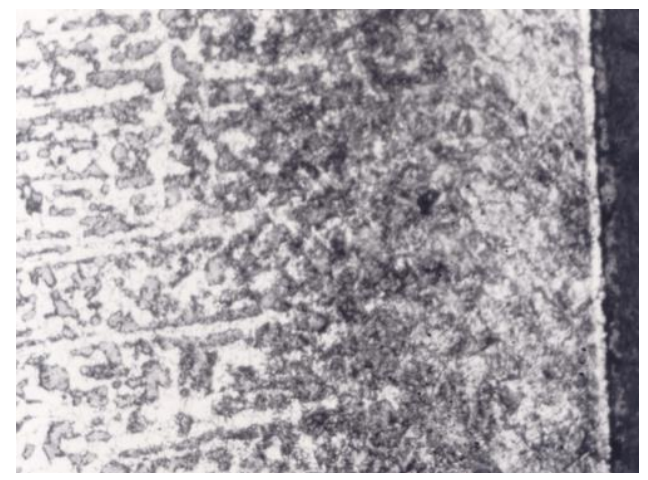

Fig. 2. Microstructure at the nitrogen plasma cut surface

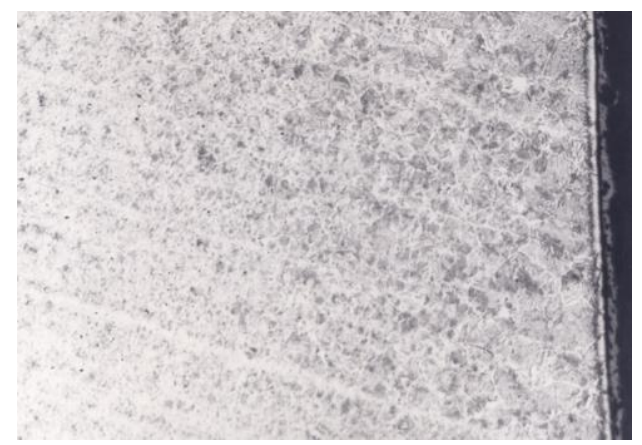

Fig. 3. Microstructure at the argon - nitrogen plasma cut surface 
A metal layer iformed at the surface cut with air plasma, which is difficult to etch. This layer seems to be like an amorphous material. It is probably a metal that has melted during the cutting process and recrystallized on the cut surface. This layer is characterized by a high hardness of about $680-750$ HV 0.2. Behind the amorphous layer appears a bainite structure with a hardness of about $500 \mathrm{HV}$ 0.2 . As it moves away from the cut surface, an overheated Widmannstätten structure appears, with a hardness of $400 \mathrm{HV} \mathrm{0.2.} \mathrm{The} \mathrm{structures} \mathrm{typical} \mathrm{for}$ welding processes (recrystallization zone, partial recrystallization zone and parent material) are also observed. Cutting with argon-hydrogen plasma causes the smallest changes in the structure and width of the HAZ. Hard, hardened layers (about $650 \mathrm{HV}$ 0.2 ) are observed near the cut surface. Behind the hardened layer, a martensitic-bainitic structure appears, with a hardness of $450 \mathrm{HV} 0.2$ and a width of about $0.3 \mathrm{~mm}$. Next, charakteristic structures of welding processes are formed. The nitrogen plasma cutting process causes similar structural changes in the cutting material as the air plasma cutting process. At the cut surface, a layer with a high hardness of 720 HV 0.2 and a width of about $0.1 \mathrm{~mm}$ is formed. Behind this layer is a wide zone of a bainite structure (about $0.4 \mathrm{~mm}$ ) and a hardness of $400-500 \mathrm{HV} 0.2$. Further there is a wide layer of recrystallization and partial recrystallization. Hardness distribution in air plasma cutting surfaces, argon-hidrogen plasma cutting surfaces and nitrogen plasma cutting surfaces is shown on Table 2.

Table 2. Hardness distribution in air plasma cutting surfaces, argon-hydrogen plasma cutting surfaces and nitrogen plasma cutting surfaces

\begin{tabular}{|l|l|l|l|}
\hline \multirow{2}{*}{$\begin{array}{l}\text { Measurement } \\
\text { distance from } \\
\text { the cut surface, } \\
\text { mm }\end{array}$} & Air plasma & $\begin{array}{l}\text { Nitrogen } \\
\text { plasma }\end{array}$ & $\begin{array}{l}\text { Argon- } \\
\text { hydrogen } \\
\text { plasma }\end{array}$ \\
\cline { 2 - 4 } & & 720 & 650 \\
\hline 0.005 & 750 & 550 & 430 \\
\hline 0.010 & 590 & 530 & 410 \\
\hline 0.015 & 550 & 480 & 400 \\
\hline 0.20 & 500 & 410 & 380 \\
\hline 0.30 & 480 & 380 & 350 \\
\hline 0.40 & 420 & 320 & 300 \\
\hline 0.50 & 370 & 230 & 220 \\
\hline 0.60 & 300 & 210 & 200 \\
\hline 0.80 & 230 & 200 & 197 \\
\hline 1.00 & 210 & 190 & 195 \\
\hline 1.20 & 200 & 195 & 193 \\
\hline 1.40 & 198 & 197 & 197 \\
\hline 1.60 & 195 & 193 & 195 \\
\hline 1.80 & 197 & 195 & 192 \\
\hline 2.00 & 195 & & \\
\hline & & & \\
\hline
\end{tabular}

\subsection{Analysis of chemical composition changes occurring at the cutting surface}

The phase analysis of the cutting material with air plasma, nitrogen plasma, argon-hydrogen plasma confirmed the presence of oxide phases of the type: $\mathrm{Fe}_{3} \mathrm{O}_{4}, \mathrm{Fe}_{2} \mathrm{O}_{3}, \mathrm{FeO}$ on the cut surface, (Figures 4-6). The width of these layers is between 20 and $40 \mu \mathrm{m}$. The presence of oxide layers in the cutting process with nitrogen plasma and argon-hydrogen plasma shows that the oxidation occurs as a result of the interaction of oxygen from the air sucked in by the plasma gases of the arc. Oxidized layers are easily removed from the cut surface.

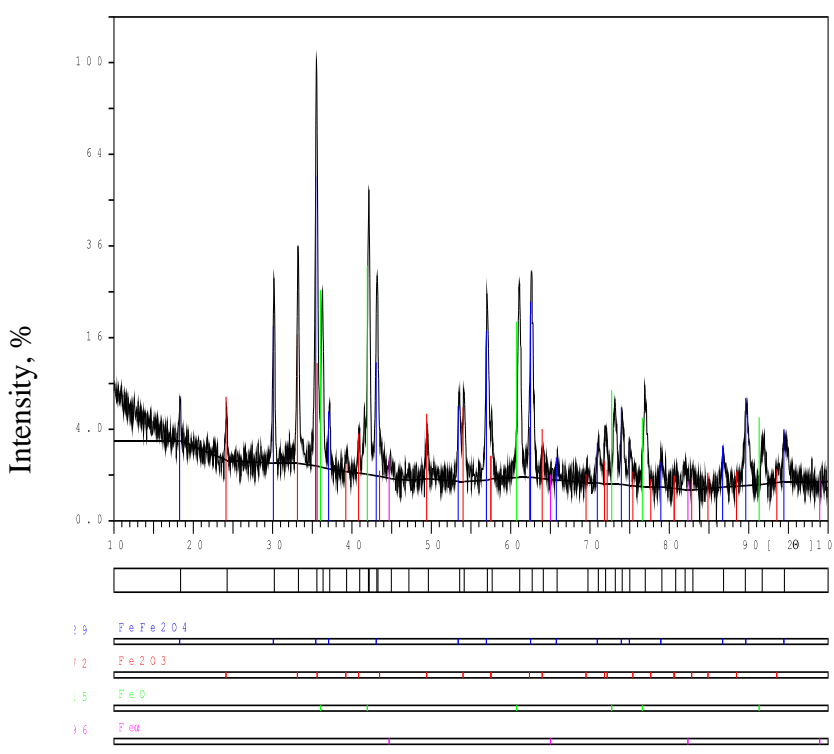

Reflection angle, $2 \Theta$

Fig. 4. X-ray phase analysis of sheet metal cut with air plasma

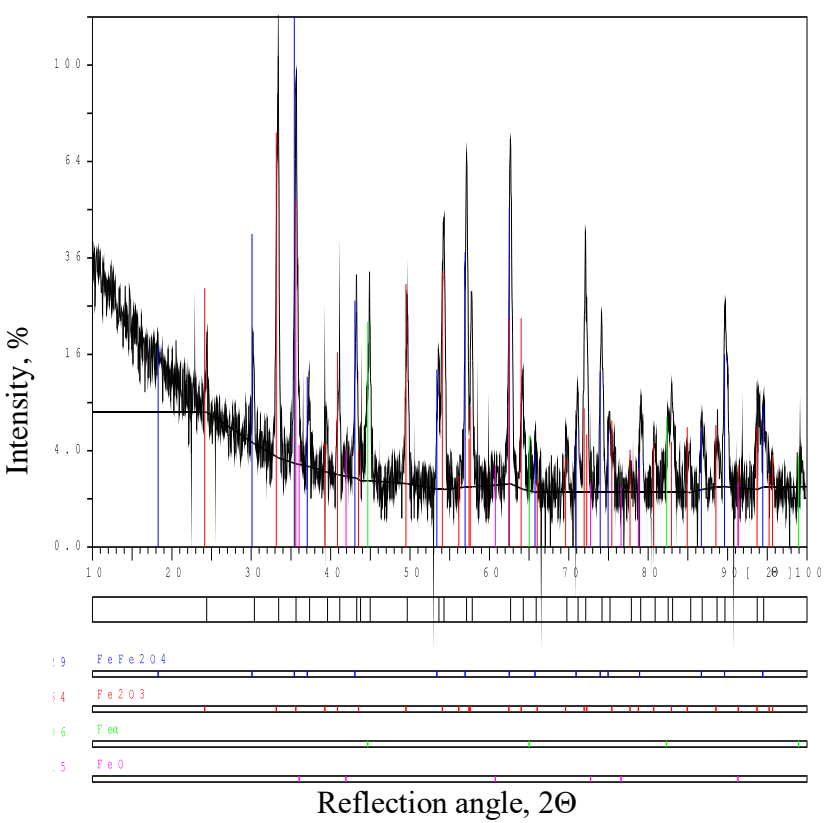

Fig. 5. X-ray phase analysis of sheet metal cut with nitrogen plasma 


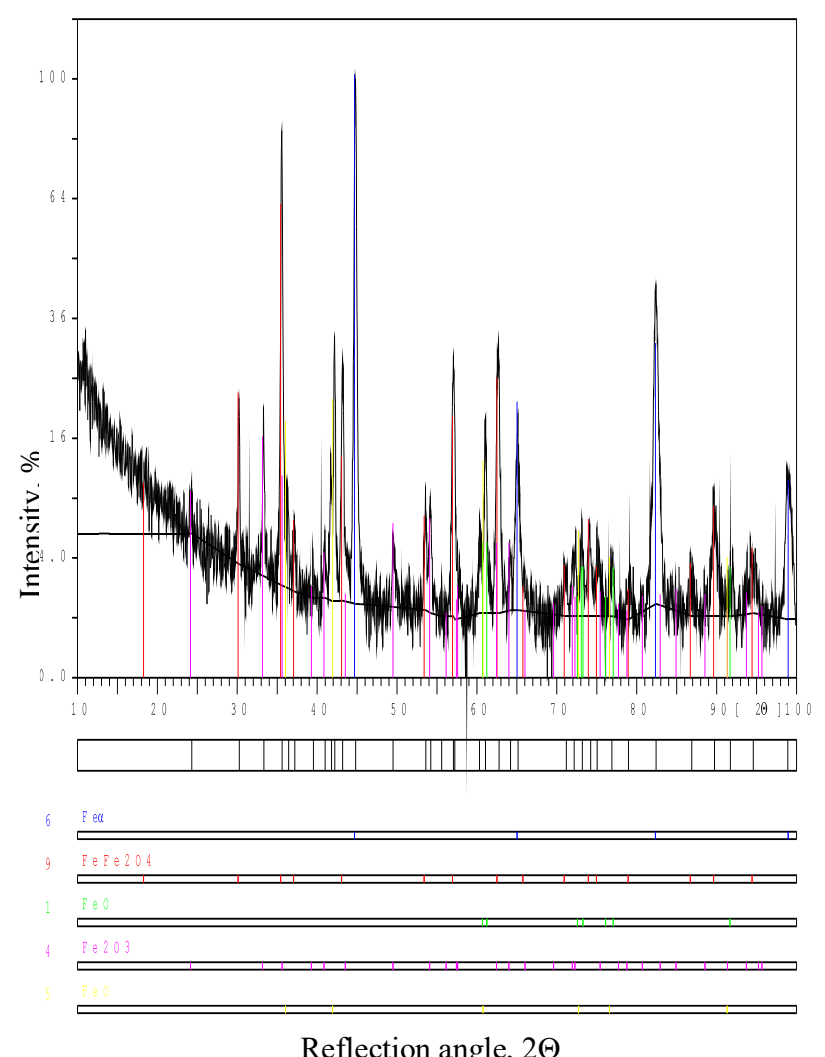

Fig. 6. X-ray phase analysis of sheet metal cut with argonhydrogen plasma

The tests of the chemical point analysis of air plasma cutting samples showed the presence of nitrogen, carbon and other chemical elements in the surface layer (Figures 7-9). During plasma cutting, nitriding of the cut surface can proceed in two ways: from plasma gases (during nitrogen plasma cutting, air plasma cutting or mixtures with nitrogen content) or from the atmosphere surrounding the plasma arc (during oxygen plasma cutting or argon plasma cutting). In the plasma arc, nitrogen dissociation and ionization takes place.

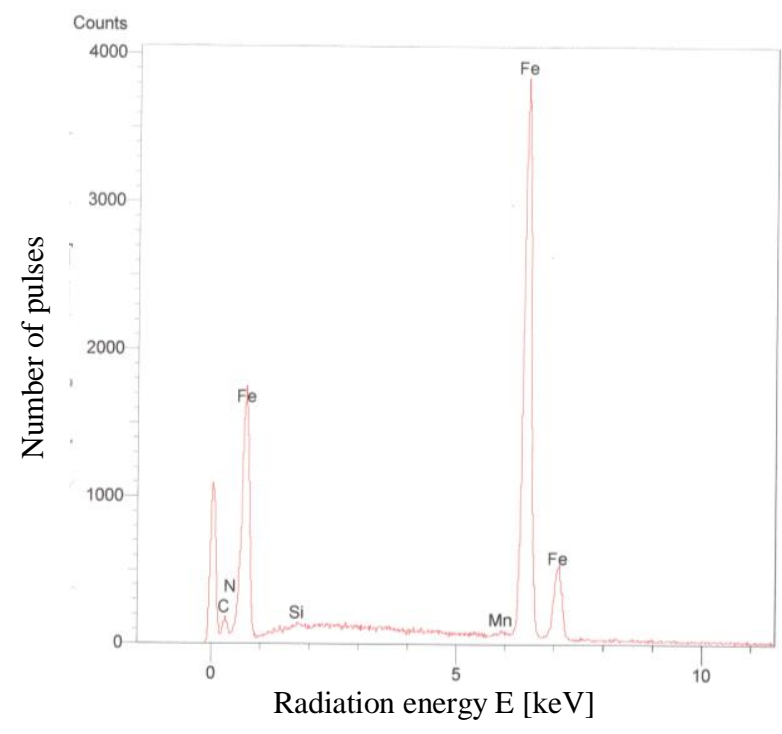

Fig. 7. Energy of scattered X-ray radiation of sheets cut with air plasma, the measurement was carried out at a distance of $20 \mu \mathrm{m}$ from the cut surface

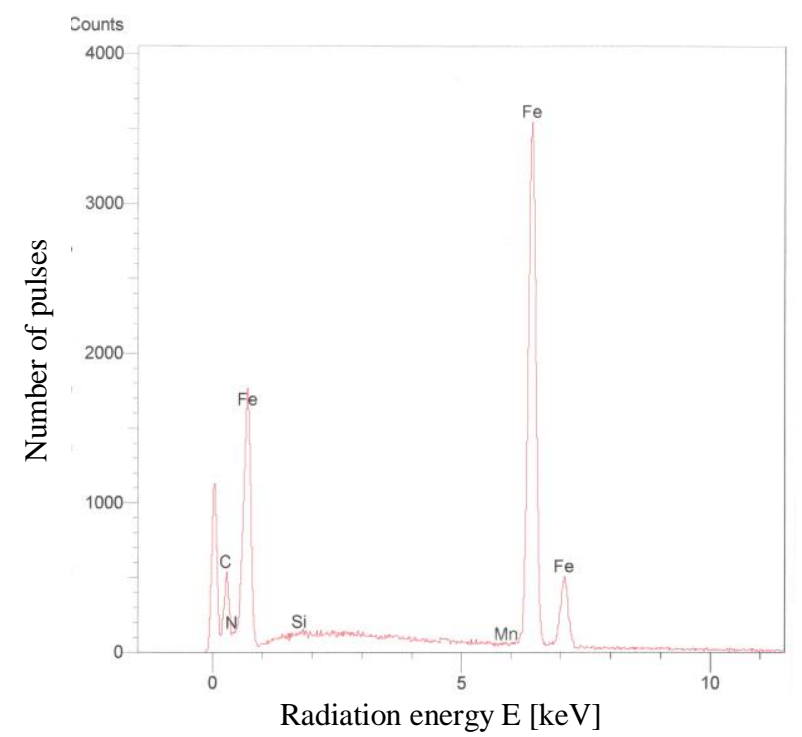

Fig. 8. Energy of scattered X-ray radiation of sheets cut with nitrogen plasma, the measurement was carried out at a distance of $20 \mu \mathrm{m}$ from the cut surface

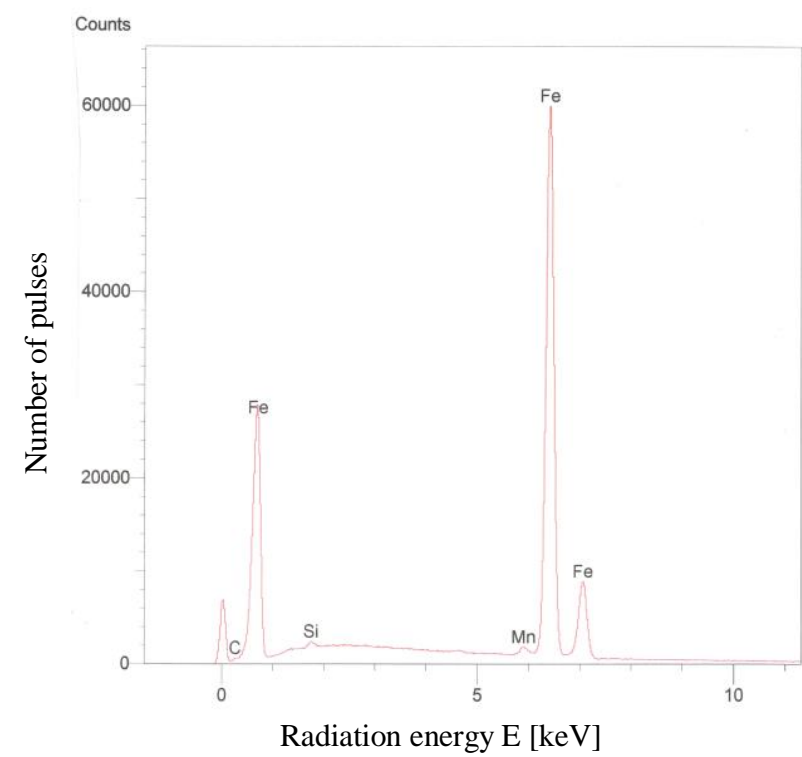

Fig. 9. Energy of scattered X-ray radiation of sheets cut with argon - hydrogen mixture plasma, the measurement was carried out at a distance of $20 \mu \mathrm{m}$ from the cut surface

In the presence of oxygen and other alloying elements, nitrogen can easily diffuse into the liquid metal. In contact with oxygen, nitrogen is oxidized according to the reaction (1):

$$
\mathrm{N}_{2}+\mathrm{O}_{2} \Leftrightarrow 2 \mathrm{NO}
$$

Nitrogen oxide dissolves easily in the liquid metal, increasing nitrogen and oxygen content (2):

$$
\mathrm{Fe}_{\mathrm{c}}+\mathrm{NO}->[\mathrm{FeO}]+[\mathrm{N}]
$$

where:

- $\mathrm{Fe}_{\mathrm{c}}$ : liquid iron,

- [FeO]: $\mathrm{FeO}$ concentration in steel, 


\section{- [N]: N concentration in steel.}

$\mathrm{Fe}_{2} \mathrm{~N}$ decomposes into $\mathrm{Fe}_{4} \mathrm{~N}$ with increasing temperature. If the temperature exceeds $550^{\circ} \mathrm{C}$, this nitride also decomposes. The conclusion is that during the cutting process in the liquid metal layer, nitrogen is in the form of a solution. Due to its properties, the air plasma arc has two effects on the cut surfaces. The microanalysis of the chemical composition showed a significant enrichment of the subsurface layers with nitrogen (about $1.6 \% \mathrm{~N}$ ) and carbon (about $0.6 \% \mathrm{C}$ ) and a strong depletion in manganese and silicon. Strong nitriding of the cut surface is the result of the action of nitrogen as a component of air plasma on the liquid metal and heating the cut surface to a high temperature. The area with the highest nitrogen content is the layer of metal that is molten and not removed by the plasma stream (hard-etching layer). The phase analysis, (Figure 10) of the air plasma cutting samples did not show the presence of nitride phases at the cut surface.

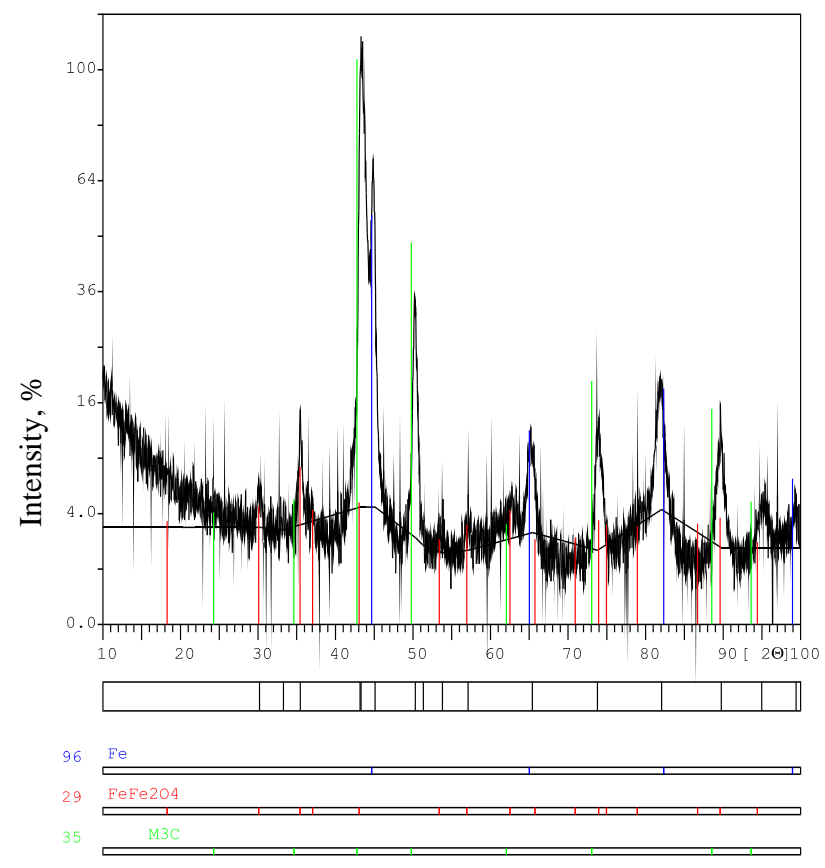

Reflection angle, $2 \Theta$

Fig. 10. Air plasma X-ray diffraction pattern

This shows that the nitrogen is probably in a dissolved state there. Probably, as a result of the very rapid heat dissipation from the cut surface, nitrogen did not have time to form compounds, but remained in the metal in the form of a supersaturated solution. Phase analysis, (Figure 10) showed the existence of carbide phases with variable carbon concentration, which confirms the enrichment of the cut surface with carbon. As a result of the air plasma cutting process, the process of carbon oxidation takes place in the initial phase of cutting. But when the liquid layer of iron oxide is formed, the carbon oxidation process ends because the carbon does not dissolve in liquid $\mathrm{FeO}$. The high oxidation rate of iron, manganese and silicon and no solubility of carbon in liquid $\mathrm{FeO}$ cause the enrichment of the molten steel with carbon and its diffusion from the metal surface into the material. Carbon diffusion in liquid steel is fast, while in the solid steel it is much slower. Therefore, there is a change in the carbon concentration as it passes from the molten area to the remaining solid metal, leading to an increase in the hardness of the cut surface. The burning of manganese and silicon from the subsurface layer can be explained on the basis of the analysis of changes in Gibbs free energies of oxide formation as a function of temperature (Figure 11). The obtained test results are compatibile with the view on selective oxidation of alloying elements. The loss of manganese and silicon is due to the greater affinity of these elements for oxygen compared to iron at the temperatures of the molten metal during the plasma cutting process. The air plasma cutting process leads to the burning of silicon at the cut surface up to $90 \%$, and manganese up to $30 \%$ in relation to the content of these elements in the parent material.

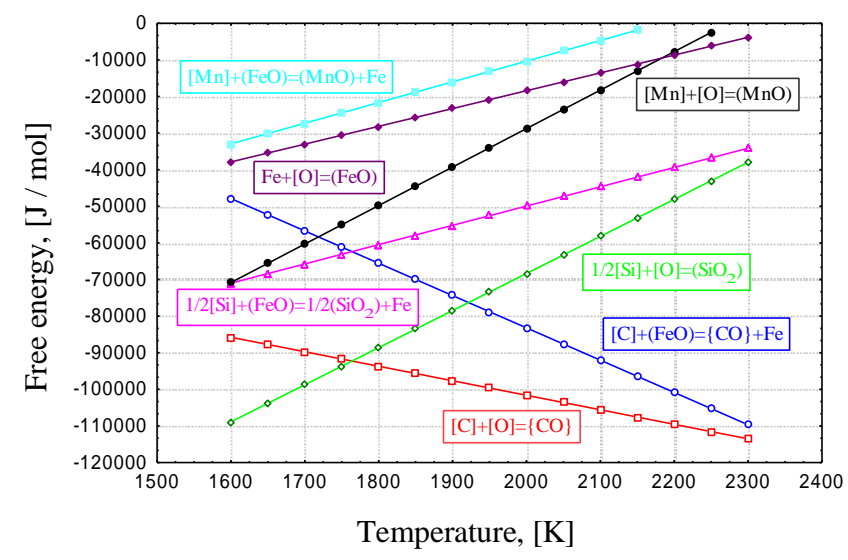

Fig. 11. The dependence of the free energy of the formation of oxides with temperature

The greater loss of silicon can be explained by the fact that silicon has a greater affinity for oxygen than manganese. The nitrogen plasma cutting process causes strong nitriding of the cut surface, up to $1.8 \%$. The width of the nitrided zone is approximately 60 $\mu \mathrm{m}$. The same as with air plasma cutting, the surface of the cut is carbonized and the alloy components are burnt. Carburization of subsurface layers is lower than with air plasma cutting and amounts to approximately $0.33 \% \mathrm{C}$. Also, the loss of manganese and silicon is lower, about $50 \%$ in relation to the content of these elements in the parent material (Figure 12). 


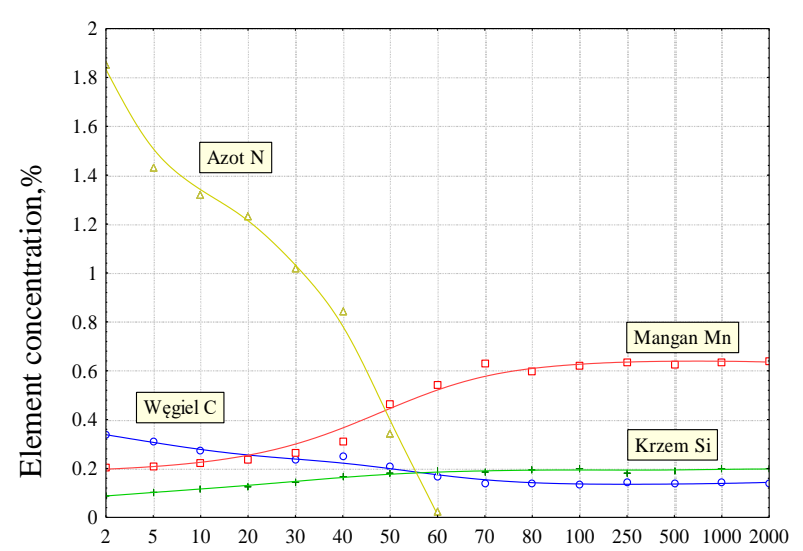

Measurement distance from the cut surface, $\mu \mathrm{m}$

Fig. 12. Change in the chemical composition that occurs in steel cut with nitrogen plasma

The argon-hydrogen plasma cutting process shows the least influence on changes in the chemical composition occurring in the cut material. This is probably due to the nature of the plasma arc gases, Figure 13. As a result of the argon-hydrogen plasma cutting process, the surface layer is slightly carburized (about $0.29 \% \mathrm{C}$ ) and manganese and silicon are lost. The width of the zones of chemical composition changes is $40 \mu \mathrm{m}$.

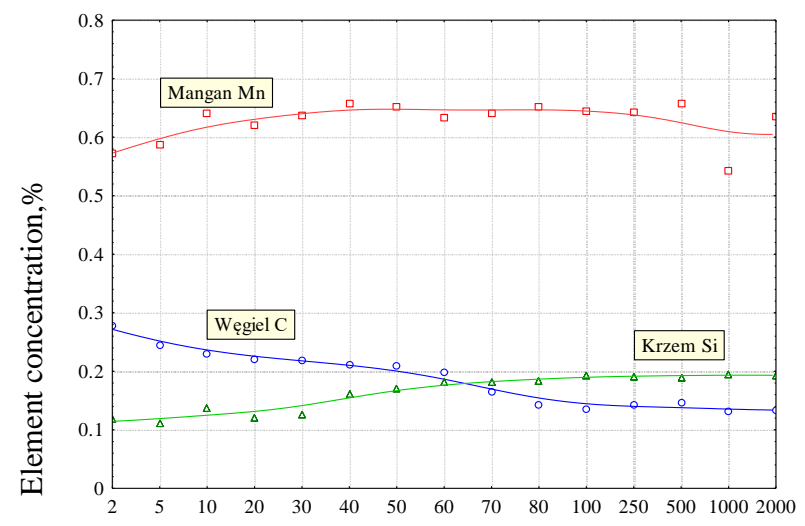

Measurement distance from the cut surface, $\mu \mathrm{m}$

Fig. 13. Change in the chemical composition that occurs in steel cut with argon - hydrogen plasma

\section{CONCLUSIONS}

As a result of the plasma cutting process on the cut surface, a layer of molten material is obtained and then solidified on the cut surface. This layer is characterized by the properties of an amorphous material that is difficult to etch. The width of this layer depends on the cutting speed and its in the range from 10 to $40 \mu \mathrm{m}$. It is very hard $(750 \mathrm{HV}$ 0.2 ) and has a high nitrogen (approximately 1.8\%) and carbon (approximately 0.5\%) content. Before welding elements which were air plasma cutting it is recommended to remove this layer mechanically.
Based on the conducted research, it can be concluded that the air plasma cutting process causes indirect changes in the cut material between argonhydrogen plasma cutting and nitrogen plasma cutting. The nitrogen plasma cutting process causes strong nitriding of the cut surface, up to $1.8 \%$, and leads to an increase in hardness above 700 HV 0.2. The width of the HAZ after nitrogen plasma cutting process is about $1.2 \mathrm{~mm}$, with a cutting speed of $\mathrm{v}=300 \mathrm{~mm} / \mathrm{min}$. The argon-hydrogen plasma cutting proces causes slight structural changes at the cut surface, has the least influence on the cutting material. The width of the HAZ after argon-nitrogen plasma cutting proces is about $0.9 \mathrm{~mm}$, at a cutting speed of $\mathrm{v}=600 \mathrm{~mm} / \mathrm{min}$. As a result of the S275JR steel cutting process with argon-hydrogen plasma, the hardness increases near the surface to about $650 \mathrm{HV} 0.2$ and there are formed small zones of changes in the chemical composition.

\section{REFERENCES}

1. Kirkpatrick I, (2000). Profile cutting - which metod?, Welding \& Metal Fabrication, 9, pp. 15-18.

2. Hidden S, (2006). Plasma Arc Cutting offers savings to concrete recycling facility, Welding Journal, 6, pp. $46-51$.

3. Hidden S., Buhler B, (2005) The Great Debate: Plasma or Oxyfuel?, Welding Journal, 3, pp. 40 - 44.

4. Górka, J., Janicki, D., Fidali, M., Jamrozik, W., (2017). Thermographic Assessment of the HAZ Properties and Structure of Thermomechanically Treated Steel, International Journal of Thermophysics, 38, 183.

5. Horst W., Markus H, (2005). Plasma cutting - an economically viable process for mild and low-alloy steels, Welding and Cutting 4, pp. $191-194$.

6. Górka J., Ploczek T, (2018). The influence of thermal cutting on the properties and quality of the cut surfaces toughened steel S 960QL, IOP Conf. Series: Materials Science and Engineering 400, pp. 1-9.

7. Zajac A., Pfeifer T, (2006). Restricting the heataffected zone during the plasma cutting of high-alloy steel, Welding International, 1, pp. 5-9.

8. Vedernikov A, (2003). Plazmennaja rezkas razdelnoj podacej dvuch gazow, Svarscik, 2003, 5, pp. 16-17.

9. Górka J., Kotarska A, (2019). MAG welding of 960QL quenched and tempered steel, IOP Conference Series: Materials Science and Engineering 591, pp. 1-8.

10. Węgrzyn, T., Piwnik, J., Hadryś, D., Wszołek, Ł., (2017). Low alloy steel structures after welding with micro-jet cooling, Archives of Metallurgy and Materials, 62(1), pp. 115-118. 
11. Górka J., Poloczek T, (2019), Thermal cutting of thermomechanically rolled S700MC and heat-treated S690QL steels, IOP Conference Series: Materials Science and Engineering 591, pp. 1-10.

12. Fydrych, D., Labanowski, J., Rogalski, G., (2013). Weldability of high strength steels in wet welding conditions, Polish Maritime Research 20(2), pp. 67-73.

13. Nakijima M, (1993). Some Aspects of Blowhole Formation in Welding of Air - Plasma out Steel Plates, JJW 1B-396-78E.

14. Willson J, (1993). Effect of Plasma Cutting with Oxygen/Nitrogen Mixtures on the Formation of Defects when MAG Welding Carbon Steels, Welding in the World, 9-10.

15. Lamikiz A., Lopez de Lacalle. (2004). $\mathrm{CO}_{2}$ laser cutting of advanced high strength steels (AHSS), Applied Surface Science, 10, pp. 362-367.

16. Górka J., Kotarska A, (2018). The quality of water jet cutting of selected construction materials, IOP Conf. Series: Materials Science and Engineering 400, pp. 1-9.

Received: February 28, 2021 / Accepted: December 20, 2021 / Paper available online: December 25, 2021 (C) International Journal of Modern Manufacturing Technologies 